\title{
Desinfecção de material de moldagem na clínica odontológica: uma revisão integrativa da literatura
}

\section{Disinfection of molding material in the daily clinic: An Integrative Literature Review}

\section{Amanda Carolini Marques de Melo' ${ }^{1}$ Daniela Maria Santos Falcão ${ }^{2}$ (1) Viviane Colares ${ }^{3}$ (1) Viviane Maria Gonçalves de Figueiredo 4 (1)}

${ }^{1}$ Autora para correspondência. Universidade Federal de Pernambuco (Recife). Pernambuco, Brasil. amandammelo48@gmail.com 2-4Universidade Federal de Pernambuco (Recife).Pernambuco, Brasil. danielamsfalcao@gmail.com, viviane.colares@upe.br, vivi_mfigueiredo@yahoo.com.br

RESUMO | INTRODUÇÃo: Fazer uso de substâncias e técnicas de desinfecção dos moldes é fundamental para prevenir a infecção cruzada durante $o$ ato da moldagem, principalmente durante a pandemia do Covid-19. OBJETIVO: Revisar a literatura de forma integrativa sobre a desinfecção de material de moldagem na clínica diária. MÉTODO: A pesquisa ocorreu pelo Lilacs e Pubmed, com a estratégia de busca ("dental impression materials" OR "disinfection techniques"). Os critérios de inclusão foram artigos completos e que abordavam os métodos de desinfecção dos materiais de moldagem. Foram selecionados: estudo clínico randomizado, revisão sistemática, estudo clínico observacional, e estudo laboratorial, publicados entre 2010 a 2020 e escritos em português, inglês ou espanhol. Os critérios de exclusão foram artigos que abordavam outras propriedades dos materiais de moldagem, relacionados somente ao fluxo digital, sobre efeitos da radiação ultravioleta no ambiente clínico, estudos sobre desinfecção do canal radicular e todas as produções que não continham as variáveis estudadas. A seleção dos artigos foi realizada com base nos resumos ou abstracts; e em seguida foi realizada a extração e análise dos dados. RESULTADOS: Os estudos clínicos e laboratoriais foram os mais prevalentes (04 artigos), Todos os desinfetantes e técnicas propostos promoveram a desinfecção dos materiais de moldagem, até mesmo a lavagem em água. O hipoclorito de sódio foi a substância mais pesquisada em diversas concentrações, assim como o hidrocolóide irreversível para os materiais de moldagem. CoNCLUSÃo: A lavagem com água, somada à ação de uma substância ou técnica de desinfecção, é favorável para redução de microrganismos sobre o molde e visa evitar a contaminação cruzada na clínica odontológica.

PALAVRAS-CHAVE: Prótese Dentária; Materiais para moldagem odontológica; Infecções por Coronavírus.
ABSTRACT | INTRODUCTION: It is essential to use substances and techniques for disinfecting the molds in order to prevent crossinfection during the act of molding. OBJECTIVE: To review the literature in an integrative way on the disinfection of impression material in the daily clinic. METHOD: The research was carried out by Lilacs and PubMed with the search strategy ("dental impression materials" OR "disinfection techniques"). The inclusion criteria were complete articles that addressed the methods of disinfecting the impression materials. Randomized clinical studies, systematic review, observational clinical study, and laboratory study published between 2010 and 2020 and written in Portuguese, English, or Spanish were selected. The exclusion criteria were articles that addressed other properties of the impression materials, related only to the digital flow, on the effects of ultraviolet radiation in the clinical environment, studies on root canal disinfection, and all productions that did not contain the studied variables. RESULTS: Clinical and laboratory studies were the most prevalent (04 articles). All the disinfectants and techniques promoted the disinfection of the molding materials, even the washing in water. Sodium hypochlorite was the most researched substance in different concentrations and irreversible hydrocolloid for impression materials. CONCLUSION: Washing with water added to the action of a substance or disinfection technique is favorable for reducing microorganisms on the mold and avoiding cross-contamination in the dental clinic.

KEYWORDS: Prosthodontics; Dental Impression Materials; Coronavirus Infections. 


\section{Introdução}

A desinfecção dos materiais de moldagem no consultório odontológico evita a propagação de doenças infecciosas e mantém a segurança dos prestadores de cuidados odontológicos.12 No mercado, há várias opções de antimicrobianos, visando a desinfecção de moldes odontológicos. Porém, existem diversos fatores que precisam ser observados, como a eficácia e composição química do produto, de maneira que não modifiquem as dimensões e reprodução de detalhes do material de moldagem utilizado., 3,4

Atualmente vivenciamos a pandemia da cepa de Coronavírus 2019 (COVID-19) que constitui um problema de saúde pública mundial, devido a sua alta virulência e disseminação. A ação deste vírus promoveu uma emergência no sistema de saúde em todo o mundo. .5 Neste momento pandêmico, o reforço na biossegurança nos procedimentos odontológicos é fundamental ${ }^{6}$, em decorrência dos ricos de infecção cruzada, como por exemplo na realização de moldagens odontológicas. Desse modo, foi recomendado o uso do fluxo digital para as impressões dentais, inclusive pelo Conselho Federal de Odontologia no Brasil, como uma forma de reduzir a cadeia de contaminação entre paciente, cirurgião-dentista, entregador e técnico em prótese dentária. $\frac{78}{8}$

Contudo, o alto custo do equipamento e a necessidade de capacitação profissional faz com que a Odontologia Digital no Brasil ainda não seja uma realidade da maioria dos consultórios e das faculdades de odontologia, que continuam a praticar o fluxo de trabalho analógico. $\stackrel{8}{N a}$ tentativa de promover a desinfecção dos materiais de moldagem, diversas substâncias químicas são propostas para uso odontológico. O espectro antimicrobiano e o tempo de ação dos desinfetantes permitem que sejam classificados em três categorias: nível alto, nível intermediário e nível baixo. Os de nível alto são capazes de inativar esporos bacterianos e todas as outras formas microbianas em períodos de exposição prolongados. Esses desinfetantes, em períodos de exposição reduzido, podem eliminar microrganismos na forma vegetativa, fungos e vírus, exceto endósporos bacterianos. Os níveis intermediários destroem microrganismos, como bacilos da tuberculose e vírus hidrofílicos em cerca de trinta minutos, mas não inativam esporos. Os de baixo nível são agentes químicos com atividade antibacteriana limitada destruindo bactérias vegetativas, fungos e vírus lipofílicos em cerca de dez minutos. ${ }^{9}$

Mais estudos são necessários para evidenciar a proposta da utilização destes agentes desinfetantes na desinfecção dos materiais de moldagem. ${ }^{10}$ Além disso, diante da condição pandêmica em que vivemos, é preciso esclarecer ao cirurgião-dentista as substâncias e técnicas de desinfecção eficazes para materiais de moldagem. Por isso, objetivou-se revisar a literatura de forma integrativa sobre a desinfecção de material de moldagem na clínica diária.

\section{Método}

\section{Pergunta norteadora}

A pergunta norteadora para o seguinte estudo foi: "Que protocolos de desinfecção dos materiais de moldagem poderiam ser realizados em moldes de pacientes submetidos a tratamento protético, para reduzir o risco de infecção cruzada?"

\section{Pico}

A Revisão Integrativa da literatura sintetiza as pesquisas disponíveis sobre a temática a ser abordada e direciona a prática fundamentando-se em conhecimento científico. Assim, a estruturação da pesquisa esteve baseada na estratégia PICO, constituída por: P (Participantes: Pacientes submetidos a tratamento protético), I (Intervenção: Desinfecção dos materiais de moldagem), C (Comparador: Não foi aplicado ao estudo) e O ("Outcomes" ou Desfechos: Riscos de infecção cruzada). 


\section{Critério de elegibilidade}

A busca foi realizada nas bases de dados: Literatura Latino-Americana em Ciências da Saúde (LILACS) (https://lilacs.bvsalud.org/) e PubMed (https://pubmed. ncbi.nlm.nih.gov/). Foram incluídos os artigos completos publicados em português, espanhol e inglês, entre 2010 e 2020, sendo a última pesquisa realizada em 03 de novembro de 2020. As palavras-chave utilizadas foram: Materiais para moldagem odontológica (Dental Impression Materials) ou Técnicas de desinfecção (Disinfection techniques). A estratégia de busca nas bases de dados foi ("dental impression materials" OR "disinfection techniques").

Os critérios de inclusão neste trabalho foram artigos completos disponíveis e que abordam os métodos de desinfecção de materiais de moldagem. Os tipos de estudos selecionados foram estudos clínicos randomizados, revisão sistemática, estudo clínico observacional e estudo laboratorial. Os critérios de exclusão foram: artigos que abordavam outras propriedades dos materiais de moldagem, fluxo digital, desinfecção do ambiente clínico, estudos sobre desinfecção do canal radicular, estudo piloto, revisão de literatura, carta ao editor, caso clínico. A seleção dos artigos foi realizada com base nos resumos ou abstracts.

\section{Seleção do estudo}

Os títulos e resumos de todos os trabalhos foram analisados por três revisores. Todos os estudos que preencheram os critérios de inclusão foram selecionados para leitura do texto completo e incluídos para extração dos dados, enquanto foram registradas as razões para a exclusão. A estratégia de busca da pesquisa está detalhada na Figura 1 de acordo com a recomendação PRISMA.

\section{Extração dos dados}

Os dados completos dos textos selecionados foram extraídos pelos três revisores. A coleta de dados foi baseada nas formas de desinfecção dos materiais de moldagem na clínica diária de forma a dispor de conhecimento para a contextualização em tempos de pandemia do Covid-19.

\section{Análise de dados}

Os dados foram coletados e incluídos em uma tabela padronizada no Word com as seguintes informações: autor e ano de publicação, tipo de estudo (nível de evidência), substância e técnica de desinfecção, metodologia e resultados. Os dados foram analisados e sumarizados.

\section{Resultados}

Esta revisão de literatura foi elencada em Técnicas de Desinfecção e Materiais de Moldagem. A seleção resultou em 6 estudos sobre o tema, na Figura 1 pode-se observar a estratégia de busca e seleção dos textos. Na base de dados LILACS foram selecionados 3 artigos e no PubMed outros 3 artigos, os quais abrangem os critérios de inclusão já mencionados. $O$ PubMed e LILACS apresentaram 1 artigo duplicado nestas bases de dados. 
Figura 1. Bases de dados, artigos incluídos, artigos excluídos, por não estarem de acordo com os critérios de inclusão, para a revisão da literatura
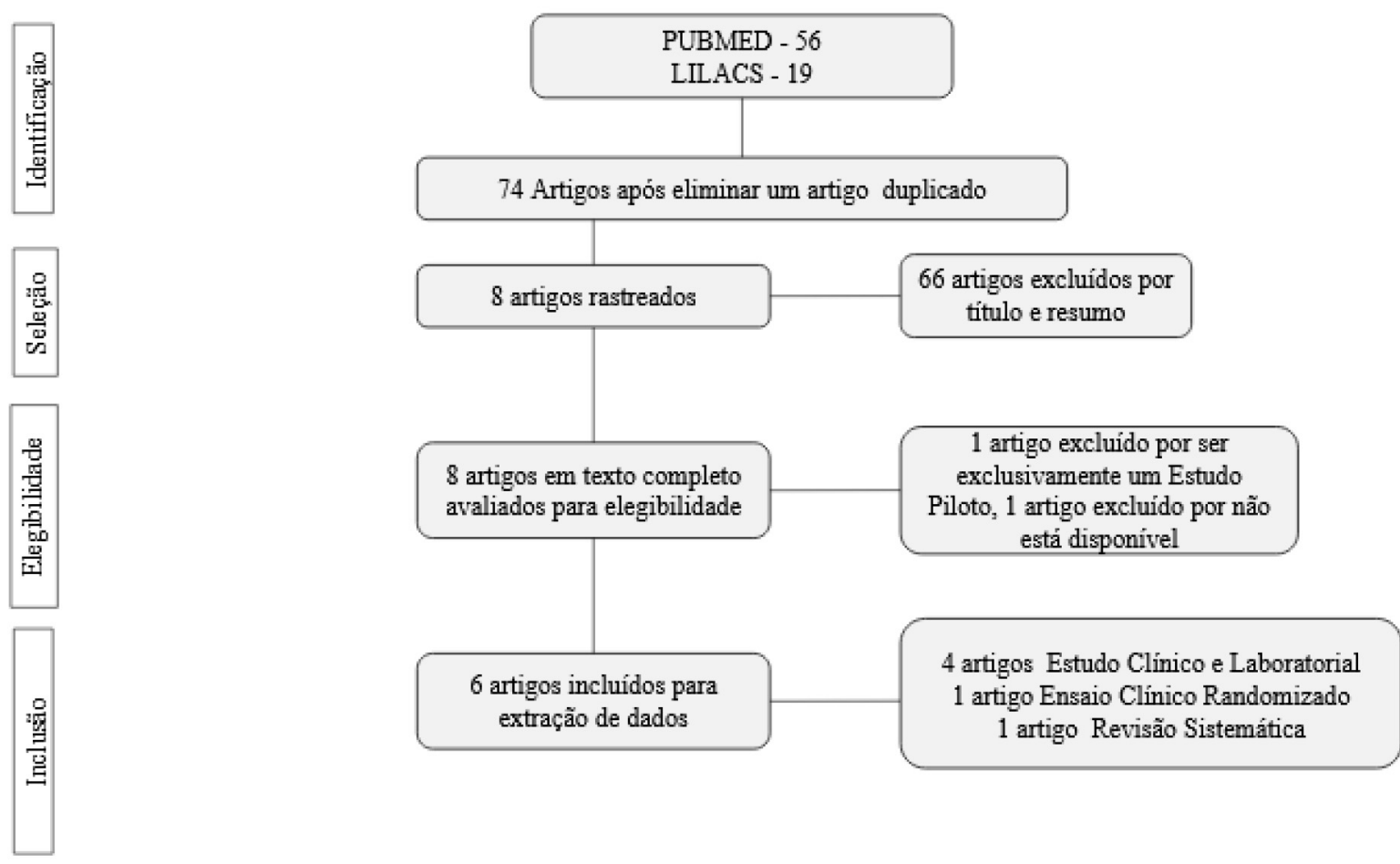

Fonte: As autoras (2021)

Todos os estudos revisados estão contemplados na Quadro 1, publicados entre 2010 e 2019. Os materiais de moldagem avaliados e os protocolos de desinfecção estão apresentados na Quadro 2. 
Quadro 1. Autor (ano), Objetivo, Tipo de Estudo (Nivel de Evidência)*, Substâncias e/ou Técnica de Desinfecção, Metodologia, Resultados (continua)

\begin{tabular}{|c|c|c|c|c|c|}
\hline $\begin{array}{l}\text { Autor } \\
\text { (ano) }\end{array}$ & Objetivo & $\begin{array}{l}\text { Tipo de Estudo } \\
\text { (Nível de } \\
\text { Evidência) }\end{array}$ & $\begin{array}{l}\text { Substâncias e/ou } \\
\text { Técnica de Desinfecção }\end{array}$ & Metodologia & Resultados \\
\hline Bustos et al. ${ }^{11}(2010)$ & $\begin{array}{l}\text { Determinar a eficácia da } \\
\text { desinfecção com soluções de } \\
\text { hipoclorito de sódio a 0,5\% e } \\
\text { glutaraldeído a } 2 \% \text { em } \\
\text { hidrocolóide irreversível e } \\
\text { silicone de condensação; e } \\
\text { analisar o efeito da } \\
\text { desinfecção na qualidade da } \\
\text { superfíie com um } \\
\text { microscópio eletrônico de } \\
\text { varredura. }\end{array}$ & $\begin{array}{l}\text { Estudo Clínico e } \\
\text { laboratorial } \\
\text { (5) }\end{array}$ & $\begin{array}{l}\text { Imersão em Hipoclorito } \\
\text { de sódio a 0,5\% (NaOCl) } \\
\text { Imersão em } \\
\text { Glutaraldeído a } 2 \%\end{array}$ & $\begin{array}{l}16 \text { pacientes participaram do estudo, assim } \\
\text { foram realizadas } 32 \text { impressões ( } 16 \text { feitas de } \\
\text { hidrocolóide irreversível e } 16 \text { feitas de } \\
\text { silicone condensação), no arco superior de } \\
\text { pacientes. O intervalo das impressões- } 72 \mathrm{hs} \text {. } \\
\text { Os materiais de moldagem foram imersos } \\
\text { nas substâncias de desinfecção. } \\
\text { Amostras obtidas e divididas em grupos: } \\
\text { controle alginato, alginato em hipoclorito de } \\
\text { sódio a } 0,5 \% \text { (NaOCl) por } 5 \text { min e } 10 \\
\text { minutos, alginato em Glutaraldeído a 2\% } \\
\text { por } 5 \text { min e } 10 \text { minutos, controle silicone, } \\
\text { silicone em NaOCl a } 0,5 \% \text { por } 5 \text { min e } 10 \\
\text { minutos, e silicone em glutaraldeído } 2 \% \text { por } \\
5 \text { min e } 10 \text { minutos. } \\
\text { Cada amostra foi dividida em dois } \\
\text { segmentos (um para o estudo } \\
\text { microbiológico e outro para o MEV). }\end{array}$ & $\begin{array}{l}\text { O número de bactérias retidas nas amostras de } \\
\text { hidrocolóide irreversível foi maior do que nas } \\
\text { amostras de silicone. } \\
\text { Os espécimes imersos em } \mathrm{NaOCl} \text { ou } \\
\text { gluteraldeído por } 5 \text { minutos apresentaram } \\
\text { efetiva desinfeç̧ão para ambos materiais de } \\
\text { moldagem. } \\
\text { A imersão em } \mathrm{NaOCl} \text { e } 0,5 \% \text { glutaraldeído a } 2 \% \\
\text { após um tempo de exposição de } 10 \text { minutos foi } \\
100 \% \text { bem-sucedida na eliminação de bactérias } \\
\text { para ambos materiais. }\end{array}$ \\
\hline Moura et al. ${ }^{12}(2010)$ & $\begin{array}{l}\text { Descontaminação de moldes } \\
\text { de hidrocolóide irreversível } \\
\text { por meio de dois métodos de } \\
\text { aplicação de vapor de } \\
\text { hipoclorito de sódio nas } \\
\text { concentrações de } 2,5 \% \text { e } \\
5,25 \% \text { por } 10 \text { minutos. }\end{array}$ & $\begin{array}{l}\text { Estudo Clínico e } \\
\text { laboratorial } \\
\text { (5) }\end{array}$ & $\begin{array}{l}\text { Vapor de Hipoclorito de } \\
\text { sódio a } 2,5 \% \text { e } 5,25 \% \\
\text { Pela caixa } \\
\text { humidificadora e pelo } \\
\text { nebulizador }\end{array}$ & $\begin{array}{l}\text { Utilizaram-se } 80 \text { moldes de hemiarcos de } 20 \\
\text { pacientes. Cada paciente teve os } 4 \\
\text { hemiarcos moldados individualmente. } \\
\text { Os moldes foram divididos em } 4 \text { grupos } \\
\text { experimentais } \\
\text { As impressões foram colocadas em vapor } \\
\text { de hipoclorito de sódio com umidade } \\
\text { relativa de } 100 \% \text { por } 10 \text { min. } \\
\text { A análise microbiológica da solução foi } \\
\text { realizada pela contagem das colônias } \\
\text { cultivadas em meio de cultura BHI-ágar } \\
\text { após } 24 \text { horas em incubadora a } 37^{\circ} \mathrm{C} \text {. }\end{array}$ & $\begin{array}{l}\text { O hipoclorito de sódio nas concentrações de } \\
2,5 \% \text { e } 5,25 \% \text { foi um desinfetante eficaz solução } \\
\text { para impressões de hidrocolóides irreversíveis. } \\
\text { Com hipoclorito de sódio a } 5,25 \% \text { não houve } \\
\text { crescimento bacteriano significativo da colônia, } \\
\text { e nenhuma diferença estatítistica entre os } \\
\text { métodos foi encontrada. } \\
\text { Pelo método caixa humidificadora as } \\
\text { concentrações de 2,5\% e 5,25\% apresentou } \\
\text { diferença significativa no número médio na } \\
\text { formação de colônias. } \\
\text { Pelo método com nebulizador não houve } \\
\text { diferença significativa no número médio de } \\
\text { colônias entre as concentrações. }\end{array}$ \\
\hline \multirow[t]{2}{*}{ Nassar et al. ${ }^{13}(2011)$} & $\begin{array}{l}\text { Investigar a literatura } \\
\text { disponível sobre a } \\
\text { estabilidade dimensional de } \\
\text { do hidrocoloide irreversível } \\
\text { em função do tempo de } \\
\text { vazamento e das soluções } \\
\text { desinfetantes utilizadas. }\end{array}$ & $\begin{array}{l}\text { Revisão Sistemática } \\
\text { (3A) }\end{array}$ & - & $\begin{array}{l}\text { Bases de dados Medline, PubMed, and } \\
\text { EMBASE. } \\
\text { Estudos in vitro foram revisados por pares } \\
\text { publicados em inglês entre o início dos anos } \\
1970 \text { e outubro de } 2010 \text {. Os critérios de } \\
\text { seleção incluíram estudos in vitro, }\end{array}$ & $\begin{array}{l}\text { Diversas substâncias, técnicas e protocolos de } \\
\text { desinfecção foram relatadas pela literatura. } \\
\text { Falta de uma tecnologia padronizada para } \\
\text { estudar o efeito das condições de } \\
\text { armazenamento, com ou sem o uso de } \\
\text { desinfetantes, torna impossível fazer } \\
\text { recomendações precisas. }\end{array}$ \\
\hline & & & & $\begin{array}{l}\text { hidrocolóide irreversível como material de } \\
\text { impressão e tempo de armazenamento. }\end{array}$ & \\
\hline
\end{tabular}


Quadro 1. Autor (ano), Objetivo, Tipo de Estudo (Nível de Evidência)*, Substâncias e/ou Técnica de Desinfecção, Metodologia, Resultados (conclusão)

\begin{tabular}{|c|c|c|c|c|c|}
\hline $\begin{array}{l}\text { Autor } \\
\text { (ano) }\end{array}$ & Objetivo & $\begin{array}{l}\text { Tipo de Estudo } \\
\text { (Nível de } \\
\text { Evidência) }\end{array}$ & $\begin{array}{c}\text { Substâncias e/ou } \\
\text { Técnica de Desinfecção }\end{array}$ & Metodologia & Resultados \\
\hline Cubas et al. ${ }^{14}(2014)$ & $\begin{array}{l}\text { Avaliar incorporação da } \\
\text { clorexidina ao pó do } \\
\text { hidrocoloide irreversível na } \\
\text { diminuição microbiana } \\
\text { durante a impressão, sem } \\
\text { afetar o desempenho do } \\
\text { material de moldagem. }\end{array}$ & $\begin{array}{l}\text { Ensaio Clínico } \\
\text { Randomizado } \\
\text { (1B) }\end{array}$ & $\begin{array}{l}\text { Incorporação da } \\
\text { Clorexidina 0,12\% ao } \\
\text { hidrocoloide irreversível }\end{array}$ & $\begin{array}{l}\text { Vinte voluntários foram divididos } \\
\text { aleatoriamente em dois grupos de acordo } \\
\text { com o líquido usado para manipulação do } \\
\text { hidrocolóide irreversível: clorexidina 0,12\% } \\
\text { ou água. } \\
\text { Amostras de saliva foram coletadas antes e } \\
\text { depois da impressão. } \\
\text { Superfícies foram avaliadas a rugosidade e a } \\
\text { estabilidade dimensional dos moldes. } \\
\text { Pesquisa esteve em acordo com as normas } \\
\text { estabelecidas pelo CONSORT. } \\
\text { Ensaio clínico randomizado triplo-cego } \\
\text { (paciente, dentista, analista microbiano). } \\
\text { No teste microbiológico foi feita a contagem } \\
\text { de colônias. }\end{array}$ & $\begin{array}{l}\text { As amostras de saliva coletadas após a } \\
\text { obtenção das impressões usando clorexidina } \\
\text { foram menos contaminadas. } \\
\text { A clorexidina misturada ao hidrocolóide } \\
\text { irreversível diminuiu a porcentagem de } \\
\text { microrganismos totais quando comparada à } \\
\text { água, e não afetou a qualidade da superfície ou } \\
\text { estabilidade dimensional dos moldes. }\end{array}$ \\
\hline $\begin{array}{l}\text { Contreras González et } \\
\text { al. }{ }^{15}(2016) .\end{array}$ & $\begin{array}{l}\text { Avaliar técnicas de } \\
\text { desinfecção sobre a } \\
\text { moldagem com silicone de } \\
\text { adição. }\end{array}$ & $\begin{array}{l}\text { Estudo Clínico e } \\
\text { laboratorial } \\
\text { (5) }\end{array}$ & $\begin{array}{l}\text { Lavagem em água } \\
\text { Imersão em } \\
\text { Glutaraldeído 2\% } \\
\text { Esterilização em } \\
\text { autoclave }\end{array}$ & $\begin{array}{l}27 \text { impressões de pacientes foram utilizadas } \\
\text { para o estudo. Foram divididas em três } \\
\text { grupos: Grupo controle, Grupo A e Grupo B } \\
\text { (n= } 9 \text { moldagens por grupo). O grupo } \\
\text { Controle sem desinfecção, moldes imersos } \\
\text { em água bidestilada por } 10 \text { minutos. } O \\
\text { grupo A as moldagens foram imersas em } \\
\text { glutaraldeído } 2 \% \text { por } 10 \text { minutos e no grupo } \\
\text { B os moldes foram esterilizados por } 15 \\
\text { minutos em autoclave a } 134^{\circ} \mathrm{C} \text {. }\end{array}$ & $\begin{array}{l}\text { Foi realizada a contagem bacteriana de cada } \\
\text { grupo do estudo e foi possível perceber que o } \\
\text { grupo Controle obteve o maior crescimento } \\
\text { bacteriano. O grupo B mostrou ausência de } \\
\text { crescimento notável. No grupo A, o } \\
\text { glutaraldeído a } 2 \% \text { eliminou microrganismos } \\
\text { não esporulados presentes nas moldagens. } \\
\text { Assim, lavar a impressão pode reduzir os } \\
\text { microrganismos, mas não a desinfeta. A } \\
\text { eliminação completa de microrganismos foi } \\
\text { alcançada esterilizando as impressões com } \\
\text { material elastomérico. }\end{array}$ \\
\hline Azevedo et al. ${ }^{16}$ (2019) & $\begin{array}{l}\text { Avaliamos a eficácia } \\
\text { antimicrobiana e o impacto } \\
\text { na estabilidade dimensional } \\
\text { das impressões de silicone } \\
\text { de adição das soluções de } \\
\text { desinfecção mais utilizadas } \\
\text { clinicamente. }\end{array}$ & $\begin{array}{l}\text { Estudo Clínico e } \\
\text { laboratorial } \\
\text { (5) }\end{array}$ & $\begin{array}{l}\text { Lavagem com água } \\
\text { Peróxido de hidrogênio } \\
3 \% \\
\text { Desinfetante comercial } \\
\text { MD520 } \\
\text { Hipoclorito de sódio } 1 \% \text { e } \\
\text { 5,25\%. }\end{array}$ & $\begin{array}{l}\text { As moldagens foram obtidas em } 16 \\
\text { pacientes. O material de impressão foi o } \\
\text { silicone de adiçã̃o e as soluções } \\
\text { desinfetantes foram peróxido de hidrogênio } \\
3 \% \text {, desinfetante comercial MD520, e } \\
\text { hipoclorito de sódio } 1 \% \text { e } 5,25 \% \text {. Os moldes } \\
\text { foram mergulhados nas soluções de } \\
\text { desinfeç̧ão. Houve uma divisão de grupos } \\
\text { em um grupo controle (não lavado), um } \\
\text { grupo lavado com água corrente o outro } \\
\text { grupo com os desinfetantes. }\end{array}$ & $\begin{array}{l}\text { A lavagem com água reduz a taxa microbiana, } \\
\text { mas em um percentual mínimo comparado } \\
\text { com o uso dos desinfetantes. Os desinfetantes } \\
\text { em teste mostraram uma redução de } 99,9 \% \\
\text { dos microrganismos presentes sobre o molde. } \\
\text { As alterações dimensionais, relacionadas ao } \\
\text { uso de desinfetantes, estavam de acordo como } \\
\text { o limite estabelecidos pelo padrão ISO: } \\
\text { 4823:2015. E a lavagem com água não } \\
\text { apresentou alterações dimensionais. }\end{array}$ \\
\hline
\end{tabular}

${ }^{*}$ Nível de evidência científica é baseada em Demathé et al. ${ }^{17}$

Fonte: As autoras (2021). 
Quadro 2. Autor (ano), Material de Moldagem, Substância e Técnica de Desinfecção e Protocolo de Desinfecção

\begin{tabular}{|c|c|c|c|}
\hline $\begin{array}{l}\text { Autor } \\
\text { (ano) }\end{array}$ & $\begin{array}{l}\text { Material de } \\
\text { Moldagem }\end{array}$ & $\begin{array}{c}\begin{array}{c}\text { Substância e Técnica de } \\
\text { Desinfecção }\end{array} \\
\end{array}$ & Protocolo de Desinfecção \\
\hline Bustos et al. ${ }^{11}(2010)$ & $\begin{array}{l}\text { Hidrocoloide } \\
\text { Irreversível } \\
\text { Silicone de } \\
\text { Condensação }\end{array}$ & $\begin{array}{l}\text { Hipoclorito de sódio a } 0,5 \% \\
\text { (NaOCl) e } \\
\text { Glutaraldeído a } 2 \% \\
\text { Imersão do material de } \\
\text { moldagem }\end{array}$ & $\begin{array}{l}\text { Hipoclorito de sódio 0,5\%: Fragmentos dos moldes foram imensos em hipoclorito de sódio } 0,5 \% \text { por } 5 \text { minutos ou } 10 \text { min para } \\
\text { cada material de moldagem; } \\
\text { Glutaraldeído a 2\%: Fragmentos dos moldes foram imensos em glutaraldeído } 2 \% \text { por } 5 \text { minutos ou } 10 \text { min para cada material de } \\
\text { moldagem; }\end{array}$ \\
\hline Moura et al. ${ }^{12}(2010)$ & $\begin{array}{l}\text { Hidrocoloide } \\
\text { Irreversível }\end{array}$ & $\begin{array}{l}\text { Vapor de Hipoclorito de } \\
\text { sódio a } 2,5 \% \text { e } 5,25 \% \text { pelo } \\
\text { método da caixa } \\
\text { humidificadora e pelo } \\
\text { método do nebulizador }\end{array}$ & $\begin{array}{l}\text { Moldes foram enxaguados com água destilada por } 15 \text { s para reduzir o número de bactérias residentes na impressão; } \\
\text { Seguido o enxague com pasta de gesso para remover o conteúdo orgânico persistente de saliva, sangue e detritos; } \\
\text { E outro enxágue com água destilada; } \\
\text { Método Caixa Humidificadora - Molde permaneceu por } 10 \text { min em caixa umidificadora (fechada) com hipoclorito de sódio a 2,5\% } \\
\text { ou 5,25\%. } \\
\text { Método Nebulizador - Molde permaneceu por } 10 \text { min em caixa fechada com vapor de hipoclorito de sódio a 2,5\% ou 5,25\% } \\
\text { obtido por um nebulizador. } \\
\text { Por fim as moldagens foram lavadas em água destilada por } 15 \text { s, para retirada de qualquer possivel hipoclorito impregnado. }\end{array}$ \\
\hline Cubas et al. ${ }^{14}(2014)$ & $\begin{array}{l}\text { Hidrocoloide } \\
\text { Irreversível }\end{array}$ & $\begin{array}{l}\text { Incorporação da } \\
\text { Clorexidina 0,12\% ao } \\
\text { hidrocoloide irreversível }\end{array}$ & A mistura seguiu a proporção padrão de pó e líquido. \\
\hline $\begin{array}{l}\text { Contreras González et } \\
\text { al. }{ }^{15}(2016) .\end{array}$ & $\begin{array}{l}\text { Silicone de } \\
\text { Adição }\end{array}$ & $\begin{array}{l}\text { Lavagem com água } \\
\text { Imersão em Glutaraldeído } \\
2 \% \\
\text { Esterilização em autoclave }\end{array}$ & $\begin{array}{l}\text { Lavagem com água: molde foi mergulhado por } 10 \text { min em água destilada. } \\
\text { Uso do Glutaraldeído a 2\%: molde foi mergulgado por } 10 \text { minutos na solução desinfetante e depois foram lavados com solução } \\
\text { fisiológica estéril. } \\
\text { Esterilização em Autoclave: molde foi autoclavado a } 134 \text { oC por15 minutos a } 15 \text { psi. }\end{array}$ \\
\hline Azevedo et al. ${ }^{16}$ (2019) & $\begin{array}{l}\text { Silicone de } \\
\text { Adição }\end{array}$ & $\begin{array}{l}\text { Lavagem com água } \\
\text { Peróxido de hidrogênio 3\% } \\
\text { Desinfetante comercial } \\
\text { MD520 } \\
\text { Hipoclorito de sódio } 1 \% \text { e } \\
\text { 5,25\%. }\end{array}$ & $\begin{array}{l}\text { Lavagem dos moldes em água corrente por } 30 \text { segundos; } \\
\text { Peróxido de hidrogênio } 3 \% \text { e Hipoclorito de sódio } 1 \% \text { e 5,25\%: Lavagem do molde em água corrente por } 15 \text { segundos, Imersão do } \\
\text { molde na substância por } 10 \text { minutos e lavagem por } 15 \text { segundos em água corrente. } \\
\text { Desinfetante comercial MD520: Lavagem do molde em água corrente por } 15 \text { segundos, Imersão do molde na substância por } 10 \\
\text { minutos e lavagem por } 15 \text { segundos em água corrente. }\end{array}$ \\
\hline
\end{tabular}

Fonte: As autoras (2021). 


\section{Discussão}

Os artigos incluídos nesta revisão de literatura apresentaram-se heterogêneos quanto ao tipo de estudo e consequentemente em relação ao nível de evidência científica. Os estudos clínicos e laboratoriais foram os mais prevalentes (04 artigos), seguido pelo estudo de revisão sistemática e o ensaio clínico randomizado que contabilizaram apenas 01 artigo cada.

O hidrocolóide irreversível foi o material de moldagem mais prevalente dentre os estudos de desinfecção. ${ }^{11-14} \mathrm{O}$ silicone de condensação ${ }^{11}$ e o silicone de adição15,16 também foram avaliados pela literatura pesquisada. Já as substâncias desinfetantes avaliadas

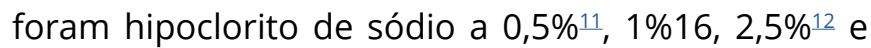
5,25\%12,16; glutaraldeído a 2\%11,15; peróxido de hidrogênio $3 \% \frac{16}{}$ e um desinfetante comercial MD520. ${ }^{\frac{16}{}} \mathrm{~A}$ incorporação da clorexidina $0,12 \%$ ao pó do hidrocolóide irreversível ${ }^{14}$, vapor de hipoclorito de sódio ${ }^{12}$ e a esterilização do molde ${ }^{15}$ foram técnicas de desinfecção testadas pela literatura.

Todos os desinfetantes e técnicas propostos nesta revisão promoveram a desinfecção dos materiais de moldagem, até mesmo a lavagem em água. Quanto à estabilidade dimensional, não houve resultados negativos nos achados. ${ }^{14,16}$ No entanto, poucos foram os estudos que abordaram as variáveis da desinfecção e da alteração dimensional. A ação e os efeitos do desinfetante na estabilidade e reprodução das impressões são fatores a serem analisados na escolha do melhor método. 4

As ações das substâncias foram mais estudadas que as técnicas de desinfecção, sendo o hipoclorito de sódio a substância mais pesquisada e apresentada em diferentes concentrações. A literatura mostrou que não houve diferença estatística entre o hipoclorito de sódio e o glutaraldeído1; ; como também não difere na efetividade quanto as concentrações 2,5\% e 5,25\% para essa substância. ${ }^{12}$ Assim como o hipoclorito de sódio não interfere na estabilidade dimensional do molde. ${ }^{16}$ Por fim, o hipoclorito de sódio é um dos desinfetantes mais utilizados na clínica diária por apresentar baixo preço, menores interações e ser acessível, apesar de não ser uma solução muito estável. ${ }^{4}$

A desinfecção dos materiais de moldagem tornouse um tema de interesse universal, pois pode ser 0 primeiro caso de contaminação microbiana durante 0 atendimento odontológico. 11 Com a pandemia do Covid-19, o alerta dos profissionais da Odontologia foi intensificado, já que essa doença apresenta uma elevada mortalidade, é de fácil contaminação e muitas vezes o portador ser assintomático.., 6

Em geral, é preciso considerar impressões dentais como um procedimento de potencial infeccioso. Há necessidade de desinfecção dos materiais de moldagem antes e após o procedimento, de preferência em uma área reservada ao lado da cadeira. Além disso, existe o risco de contaminação cruzada ao transportar moldes para os laboratórios de prótese, e, por isso, a desinfecção deve ter duas vias de ação.?

A limitação desta revisão de literatura se deve à proposta ser integrativa e não sistemática, bem como apresentar a busca em apenas duas bases de dados. Os ensaios clínicos são escassos nessa temática, prevalecendo estudos clínicos e laboratoriais, os quais apresentam menor evidência científica. Assim, gera limitações na extrapolação dos resultados para a clínica diária. Além disso, os achados estão restritos ao hidrocolóide irreversível e silicones, não abordando materiais anelásticos e outros elastômeros.

Os estudos revisados apresentavam variabilidade nas metodologias e poucos foram os materiais avaliados. Essa situação dificultou o agrupamento das variáveis e recomendações precisas, quanto ao uso e aplicação das substâncias desinfetantes. Desse modo, não foi possível definir a melhor substância, técnica e protocolo de desinfecção para os diversos materiais de moldagem. Vale destacar que quando foi adotado um desinfetante, os estudos utilizaram a técnica da imersão e não a borrifação da substância. A imersão apresenta inúmeros benefícios, como permitir o contato da substância com todas as superfícies do material de moldagem. ${ }^{4}$

Novos estudos devem observar a desinfecção de outros materiais de moldagem, por meio de estudos clínicos controlados, comparar a ação da imersão e spray das substâncias de desinfecção, observar outras técnicas de desinfecção e verificar a substância eficaz para o combate do vírus do Covid-19 na clínica odontológica. 


\section{Conclusão}

Ao revisar a literatura sobre a desinfecção de material de moldagem na clínica diária, verificou-se que a lavagem com água, somado à ação de uma substância ou técnica de desinfecção, é favorável para redução de microrganismos sobre o molde, visando evitar a contaminação cruzada na clínica odontológica.

\section{Contribuições das autoras}

Melo ACM e Falcão DMS participaram da seleção dos artigos, extração e análise dos dados e redação do artigo cientifico. Figueiredo VMG participou da concepção do estudo, análise dos dados e redação do artigo. Colares $\vee$ participou da redação final do artigo cientifico.

\section{Conflitos de interesses}

Nenhum conflito financeiro, legal ou político envolvendo terceiros (governo, empresas e fundações privadas, etc.) foi declarado para nenhum aspecto do trabalho submetido (incluindo, mas não se limitando a subvenções e financiamentos, participação em conselho consultivo, desenho de estudo, preparação de manuscrito, análise estatística, etc.).

\section{Referências}

1. Chidambaranathan AS, Balasubramanium M. Comprehensive review and comparison of the disinfection techniques currently available in the literature. J Prosthodont 2019;28(2):e849-56. https://doi.org/10.1111/jopr.12597

2. Barenghi L, Barenghi A, Cadeo C, Di Blasio A. Innovation by Computer-Aided Design/Computer-Aided Manufacturing Technology: A Look at Infection Prevention in Dental Settings. Biomed Res Int. 2019;2019:6092018. https://doi. org/10.1155/2019/6092018

3. Rentzia A, Coleman DC, O'Donell MJ, Dowling AH, O'Sullivan M. Disinfection procedures: their efficacy and effect on dimensional accuracy and surface quality of an irreversible hydrocolloid impression material. J Dent. 2011;39(2):133-40. https://doi. org/10.1016/j.jdent.2010.11.003

4. Arroyo Pérez CA., Basauri Esteves RL, Arroyo Moya JC. Desinfección de las impresiones dentales, soluciones desinfectantes y métodos de desinfección. Revisión de literatura. Odontol Sanmarquina 2020;23(2):147-55. http://dx.doi. org/10.15381/os.v23i2.17759
5. Izzetti R, Nisi M, Gabriele M, Graziani F. Transmissão de COVID-19 na prática odontológica: breve revisão das medidas preventivas na Itália [Internet]. J Dent Res 2020;1-9. Disponível em: https://acervomais.com.br/index.php/saude/article/ download/3487/2094/

6. Machado GM, Kasper RH, Busato ALS, Vinholes J. Biossegurança e retorno das atividades em odontologia: aspectos relevantes para enfrentamento de covid-19. STOMATOS [Internet]. 2020;26(50):30-45. Disponível em: http://posgrad.ulbra.br/ periodicos/index.php/stomatos/article/view/6035/3824

7. Papi P, Di Murro B, Penna D, Pompa G. Digital prosthetic workflow during COVID-19 pandemic to limit infection risk in dental practice. Oral Dis. 2021;27(Suppl 3):723-6. https://doi. org/10.1111/odi.13442

8. Conselho Federal de Odontologia. Recomendações Para Atendimentos Odontológicos em Tempos de Covid-19 [Interrnet]. Brasília: Conselho Federal de Odontologia; 2020. Disponível em: https://website.cfo.org.br/wp-content/uploads/2020/03/MaterialCoronavi\%CC\%81rus-Dentistas-CFO.pdf

9. Kalil EM, Costa AJF. Desinfecção e esterilização [Internet]. Acta Ortop Bras. 1994;2(4):1-4. Disponível em: https://docs.ufpr. br/ microgeral/arquivos/pdf/pdf/Esterilizacao.pdf

10. Fonseca DR, Souza PB, Dumont CV, Paiva PCP, Gonçalves PF, Santos MH. Avaliação anti-microbiológica do ácido peracético como desinfetante para moldes odontológicos. Arq Odontol [Internet]. 2011;47(3):112-8. Disponível em: http://revodonto. bvsalud.org/pdf/aodo/v47n3/a01v47n3.pdf

11. Bustos J, Herrera R, González U, Martínez A, Catalán A. Effect of inmersion desinfection with $0.5 \%$ sodium hypochlorite and $2 \%$ glutaraldehyde on alginate and silicone: Microbiology and SEM study. Int J Odontostomat [Internet]. 2010;4(2):169-77. Disponível em: https://scielo.conicyt.cl/pdf/ijodontos/v4n2/art11.pdf

12. Moura CDVS, Moura WL, França FMG, Martins GAS, Feltrim PP, Zanetti RV. Disinfection of irreversible hydrocolloid impressions with sodium hypochlorite steam: Assessment of antimicrobial efficacy. Rev Odonto Ciênc [Internet]. 2010;25(2):182-7. Disponível em: http://revodonto.bvsalud.org/pdf/roc/v25n2/15.pdf

13. Nassar U, Aziz T, Flores-Mir C. Dimensional stability of irreversible hydrocolloid impression materials as a function of pouring time: a systematic review. J Prosthet Dent. 2011;106(2):126-33. https://doi.org/10.1016/S00223913(11)60108-X

14. Cubas G, Valentini F, Camacho GB, Leite F, Cenci MS, PereiraCenci T. Antibacterial efficacy and effect of chlorhexidine mixed with irreversible hydrocolloid for dental impressions: a randomized controlled trial. Int J Prosthodont. 2014;27(4):363-5. https://doi.org/10.11607/ijp.3688 
15. Contreras González F, Tinoco Cabriales VC, Méndez Maya R, Todd Jiménez $\mathrm{M}$, Llamas del Olmo FJ. Estudio de dos técnicas de desinfección en un material de impresión. Rev ADM [Internet]. 2016;73(1):17-22. Disponível em: https://www.medigraphic.com/ pdfs/adm/od-2016/od161e.pdf

16. Azevedo MJ, Correia I, Portela A, Sampaio-Maia B. A simple and effective method for addition silicone impression disinfection. J Adv Prosthodont. 2019;11(3):155-61.https://doi.org/10.4047/ jap.2019.11.3.155
17. Demathé A, Silva ARS, De Carli JP, Goiato MC, Miyahara GI. Odontologia baseada em evidências: otimizando a prática e a pesquisa. RFO UPF [Internet]. 2012;17(1):96-100. Disponível em: http://revodonto.bvsalud.org/pdf/rfo/v17n1/a18v17n1.pdf 